\title{
SINGLE-PHASE LAMINAR FLOW HEAT TRANSFER FROM CONFINED ELECTRON BEAM ENHANCED SURFACES
}

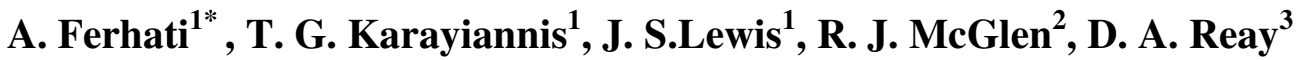 \\ ${ }^{1}$ Brunel University London, Uxbridge, Middlesex, UB8 3PH, UK \\ ${ }^{2}$ Thermacore Europe, Ashington, Northumberland, NE63 8QW, UK \\ ${ }^{3}$ David Reay and Associates, UK
}

${ }^{1}$ Corresponding author: Tel.: +44 (0) 1895267 120, Fax: +44 (0) 1895256392
E-mail address: arben.ferhati@ brunel.ac.uk 


\section{ABSTRACT}

An experimental investigation of the thermal-hydraulic characteristics for single-phase flow through three electron beam (EB) enhanced structures was conducted with water at mass flow rates $0.005 \mathrm{~kg} / \mathrm{s}$ to $0.045 \mathrm{~kg} / \mathrm{s}$. The structures featured copper heat transfer surfaces, approximately $28 \mathrm{~mm}$ wide and $32 \mathrm{~mm}$ long in the flow direction, with complex $3 D$ electron beam manufactured pyramid-like structures. The channel height varied depending on the height of the protrusions and the tip clearance was maintained at 0.1-0.3 $\mathrm{mm}$. The average protrusion densities for the three samples $S 1, S 2$, and $S 3$ were 13, 11, and 25 per $\mathrm{cm} 2$ with protrusion heights of 2.5, 2.8 and $1.6 \mathrm{~mm}$ respectively. The data gathered were compared to that for a smooth channel surface, operating under similar conditions. The results show an increase up to approximately three times for the average Nusselt number compared with the smooth surface. This is attributed to the surface irregularities of the enhanced surfaces, which not only increase the heat transfer area but also improve mixing, disturb the thermal and velocity boundary layers and reduce thermal resistance. The increase in heat transfer with the enhanced surfaces was accompanied by an increase of pressure drop, which has to be considered in design. 


\section{INTRODUCTION}

As the economy shifts from paper-based, to electronic information management, requirements for higher storage capacities and faster processing, communication and networking are essential for the proper functioning of private and government sectors. Data and computer centres are found in nearly every sector of the economy: financial, public services, media, telecommunication, universities, military, government institutions, and many others use computers and operate data centres to facilitate everyday processes, information management, and communications functions. The electronics sector has become an integral part of economic and social development around the world. Requirements for higher processing speed, faster electronic communication and miniaturization have led the way to multiprocessing and denser circuit architecture. Increased integrated circuit densities in microchips entail higher volumetric heat generation rates. As a consequence, thermal management constitutes a major challenge for further developments in the electronic sector. In particular, there is a growing demand for effective and reliable thermal management technologies able to dissipate high heat fluxes [1].

Natural and forced convection air cooling is still used in many applications. However, it can only provide moderate thermal performance and fins are usually employed on the airside to increase the surface area and heat transfer rate. Moreover, the continuous requirement for higher power and smaller volumes has made air cooling techniques inadequate in ensuring the required operating conditions, reliability and thermal stability. Single-phase liquid cooling and two-phase flow boiling combined with enhancement techniques are envisaged as solutions to this problem.

Heat transfer enhancement techniques are of interest to many sectors including energy generation, domestic (cooling and heating), chemical, automotive, turbo-machinery and 
electronics cooling. They are successfully applied to heat transfer processes in these application areas to achieve efficient and compact units. In recent years, a variety of techniques have been developed for the enhancement of heat transfer. They can be classified in three main groups: (a) passive techniques, (b) active techniques, which require additional external power, and (c) compound techniques, involving a combination of techniques to achieve a greater enhancement than a single technique alone, [2-5].

Passive techniques such as coated surfaces, roughness, fins, ribs, blocks and microchannels applied to surfaces to improve convection heat transfer have been studied by Bejan A, Sara O. N, Wang Q, Dong J, Webb R. L, and Yang K, [5-10]. Considerable information on single phase heat transfer in small/micro passages was included in a review by Rosa et al. [11]. Recently, attention has moved towards micro-pin-fin structures, [12-20]. Developments in processing techniques such as electron beam, micro deformation and selective laser melting allow complex micro-sized geometries to be fabricated in a wide range of conductive materials. This interest in developing microstructures with high thermal effectiveness is shown in the research of Siddique M, Siu-Ho A.M, Naphon P, and Wong M, [21-24].

Thermacore Europe and TWI have collaborated on a project to create enhanced heat transfer surfaces using an electron beam (EB) technology known as Surfi-Sculpt. This new surface modification technique developed at TWI is considered to have the potential for producing sculpted surfaces that will improve heat transfer in single-phase flow, pool boiling and flow boiling applications. In this process the electron beam is manipulated using a system of hardware and complex beam guidance programs. The power beam is deflected rapidly over a surface to create specially tailored features. As the beam is moved across the surface it melts and begins to vaporize the substrate material. Under the combined effects of the vapour pressure and surface tension, molten material is displaced in the direction opposite to 
the beam travel. Repeated beam passes through the same or overlapping locations results in cumulative growth of protrusions above the original surface level, accompanied by associated cavities in the substrate. An entire array of protrusions can be created simultaneously across the surface of a workpiece. By accurate control of the EB process a wide variety of welldefined patterns is possible; see [25 - 26]. The process can be used on a range of metals, polymers, ceramics and glasses and takes only a few seconds to process a square centimetre of surface, depending on the feature complexity.

In this paper, the first results are presented from experiments conducted to evaluate the thermal-hydraulic performance of the EB surface enhancement technology described above. Test samples were prepared in the form of liquid-cooled cold plates incorporating a confined EB enhanced heat transfer surface. Three different surface patterns were produced for testing, designated as S1, S2 and S3 respectively, as shown in Figure 1. In test sample S1, the surface protrusions created by the EB process form four-bladed groups arranged on a repeating square pattern. Test samples S2 and S3 both feature pyramidal-like protrusions arranged in staggered rows, but have different protrusion sizes and protrusion spacing.

Heat transfer and pressure drop tests were performed with deionized water as the working fluid. The experiments covered a range of electrical power heating inputs from 100 W to over $600 \mathrm{~W}$ with mass flow rates from $0.005 \mathrm{~kg} / \mathrm{s}$ to $0.045 \mathrm{~kg} / \mathrm{s}$. The data gathered for the EB enhanced surfaces are compared to results obtained with a smooth surface under the same heat input and flow rate conditions. The experimental pressure drops for the smooth sample are compared in terms of friction factor with the methodology described by Shah and London [27]. Furthermore the experimental heat transfer data have been compared in terms of Nusselt-number to an existing correlation for developing flows [28].

Take in figure 1 


\section{EXPERIMENTAL FACILITY}

Figure 2 shows a schematic diagram of the flow loop used to supply deionised water to the test sample at the required conditions. The fluid is supplied at a precisely controlled temperature $20{ }^{0} \mathrm{C}$ and pumped around the loop by a recirculation chiller unit (LabTech, H150-1500). The flow of water passing through the test sample is regulated by a precision control valve in the main loop and adjustment of a bypass valve. A Coriolis mass flowmeter (Endress+Hauser, Promass $40 \mathrm{E}$ ) with accuracy $0.05 \%$ is used to measure the mass flow rate and a differential pressure transducer (Omega MM Series) with accuracy $0.05 \%$ is connected to measure the pressure drop of the water across the heat transfer section in the test sample. A micro filter is fitted upstream of the test sample to remove any solid particles suspended in the fluid. Water exiting the test sample is returned to the chiller unit.

Take in figure 2

The test module assembly depicted in Figure 3 consists of three main components: the heater block, the test sample, and the transparent polycarbonate cover. The heater block material is copper $\mathrm{C} 101$. The block is $100 \mathrm{~mm}$ high with a rectangular cross-section ( $28 \mathrm{~mm} \times 32 \mathrm{~mm}$ ) matching the heat transfer surface base area in the test sample. Four cartridge heaters, each of $500 \mathrm{~W}$ power rating, $60 \mathrm{~mm}$ long and $10 \mathrm{~mm}$ diameter, are installed in the lower part of the block. The electrical power supplied to the cartridge heaters is set using a power supply and measured with a power meter. The distance between the end of the cartridge heaters and the base of the test sample is $40 \mathrm{~mm}$, allowing one-dimensional heat conduction to become established in the upper part of the block. Temperatures are measured at four positions along the vertical axis of the heater block. The top thermocouple is located $2.3 \mathrm{~mm}$ below the top surface of the block and the remainder are equally spaced $4 \mathrm{~mm}$ apart. In order to quantify 
the longitudinal temperature variation along the top surface of the heater block two additional thermocouples are located $3.5 \mathrm{~mm}$ from the upstream and downstream end faces. All heater block temperatures are measured with $0.75 \mathrm{~mm}$ diameter type- $\mathrm{T}$ sheathed thermocouples, which are secured into $1.0 \mathrm{~mm}$ diameter $\mathrm{x} 14 \mathrm{~mm}$ deep holes with thermally conductive compound.

Take in figure 3

The test samples were manufactured from $6.5 \mathrm{~mm}$ thick copper (C101) plate blanks $55 \mathrm{~mm}$ long $\mathrm{x} 35 \mathrm{~mm}$ wide. A flow space was machined in each test sample, reducing the base thickness to $3 \mathrm{~mm}$. The EB treatment was then applied to a central area approximately $28 \mathrm{~mm}$ wide and $32 \mathrm{~mm}$ long in the flow direction, as shown in Figure 4. The untreated sections at both ends of the flow space $(7.5 \mathrm{~mm}$ long) provide smooth inlet and outlet surfaces

Take in figure 4

As discussed in the Introduction, different surface protrusion patterns were applied to the three EB enhanced samples S1, S2 and S3. Magnified photographic images of the surfaces were utilized to estimate the transverse spacing $\left(\mathrm{S}_{\mathrm{T}}\right)$ between protrusions and the longitudinal spacing $\left(\mathrm{S}_{\mathrm{L}}\right)$ between protrusion rows. The height of protrusions $\left(\mathrm{H}_{\mathrm{P}}\right)$ above the untreated substrate surface was checked at several points on each test sample using an electronic height gauge (TESA, micro-hite 350) with accuracy $\pm 0.0001 \mathrm{~mm}$. It should be recalled that in addition to the formation of protrusions, the EB process creates associated cavities in the substrate surface. Values of $S_{T}, S_{L}$ and $H_{P}$ for test samples $S 1, S 2$ and $S 3$, determined as outlined above, are listed in the Table 1. The average protrusion densities for samples S1, S2, and S3 are 13,11 and $25 / \mathrm{cm}^{2}$ respectively. The test sample is vacuum brazed to the top of the heater block to ensure good thermal contact. 
A transparent polycarbonate cover, $21 \mathrm{~mm}$ thick, is fitted to each test sample. The cover forms the upper surface of the flow channel over the test sample heat transfer surface and permits visual observation. Transverse slots, $18 \mathrm{~mm}$ deep x $7.5 \mathrm{~mm}$ wide, are cut in the cover at each end to act as inlet and outlet plenums. The channel flow length $\mathrm{L}$ between the plenums is $32 \mathrm{~mm}$. Holes are drilled through the cover to provide static pressure tapping points $2.7 \mathrm{~mm}$ downstream of the channel entry and $2.7 \mathrm{~mm}$ upstream of the channel exit. The plenums accommodate the flow connections and type-T thermocouples to measure the inlet and outlet water temperatures. By integrating these connections and measurement points in the cover, the thickness of the copper test sample is kept low, thus reducing heat losses from the sides. The low thermal conductivity of polycarbonate $(\mathrm{k}=0.2 \mathrm{~W} / \mathrm{m} \mathrm{K})$ ensures that the cover can be treated as adiabatic.

The height of the flow channel $H_{c h}$ above the test sample heated surface is governed by the size of a step machined around the edge of the polycarbonate cover, locating it in the copper test sample. For the EB enhanced test samples, the step size was adjusted to maintain a clearance between the top of the protrusions and the cover. This clearance varied between about $0.1 \mathrm{~mm}$ and $0.3 \mathrm{~mm}$ as a result of the different protrusion heights and clearances. The flow cross-sectional area $A_{c}$ is based on the channel geometry and does not take in account the enhancement, and is evaluated as product of $W_{c h}$ (channel width) and $H_{c h}$ (channel height). Values of $H_{c h}$ and $A_{c}$ are listed in Table 1. For the smooth surface test sample the channel height and width are $2.45 \mathrm{~mm}$ and $28.0 \mathrm{~mm}$ respectively, corresponding to a free flow area of $68.6 \mathrm{~mm}^{2}$, an aspect ratio of 11.4 (channel width/channel height) and a hydraulic diameter $D_{h}$ of $4.51 \mathrm{~mm}$. 
A $10 \mathrm{~mm}$ thick PTFE enclosure is fitted around the test module assembly to provide thermal insulation. Figure 5 shows a schematic view of the integrated test module assembly.

Take in figure 5

A data acquisition system, comprising a Pico Technology TC-08 data logger interfaced to a personal computer running PicoLog software, is used to measure, record and display the temperature sensor and pressure transducer outputs. Readings of each measured variable are acquired at one second intervals. The water temperatures at inlet and outlet from the test sample and the heater block temperatures are measured using calibrated type-T thermocouples with an uncertainty of $\pm 0.2 \mathrm{~K}$. The differential pressure transducer with a range of $2.5 \mathrm{kPa}$ and an accuracy of $0.05 \%$ of full-scale was used to measure the pressure drop between the channel tapping points shown in Figure 5. For higher pressure drops that arose for sample $\mathrm{S} 3$, the same model pressure transducer with a range $17 \mathrm{kPa}$ and accuracy $0.05 \%$ was used. The Coriolis flow-meter used to measure the mass flow rate of the water is calibrated for flow rates up to $0.11 \mathrm{~kg} / \mathrm{h}$ and has a specified accuracy of $\pm 0.05 \%$ of reading.

Testing of the three EB enhanced surfaces and the smooth surface were conducted in nine steps for a range of mass flow rates of deionised water from $0.005 \mathrm{~kg} / \mathrm{s}$ to $0.044 \mathrm{~kg} / \mathrm{s}$. The water inlet temperature was maintained close to $20^{\circ} \mathrm{C}$ for all tests. Pressure drop and heat transfer data, were recorded at six values of power input that ranged from $100 \mathrm{~W}$ to $600 \mathrm{~W}$. The electrical power supplied to the cartridge heaters is set using a power supply (EA Elektro-Automatik, EA-PS 9080-50) and measured with a power meter (Hameg, HM8115-2) accurate to $\pm 0.8 \%$. 
Pressures and temperatures were monitored to ensure that steady conditions are established before experimental data were collected. Measurements were recorded at one second intervals for a minimum period of $5 \mathrm{~min}$, after readings remained constant for at least $15 \mathrm{~min}$. The recorded values for each measured variable were then averaged and the mean values were stored as the steady-state measurements for the particular test condition.

\section{DATA ACQUISITION}

\section{Friction factor}

The recorded temperatures, flow rate, and pressure drop were utilised to compute the average convection heat transfer coefficient and friction factor, respectively. All fluid properties were calculated at the bulk mean temperature, i.e. average between inlet and outlet. The Reynolds number is evaluated based on the maximum velocity through the enhanced structure:

$$
\operatorname{Re}_{D_{h}}=\frac{\rho V_{\max } D_{h}}{\mu}
$$

The maximum velocity $V_{\max }$ is determined as:

$$
V_{\max }=\frac{m}{\rho A_{\min }}
$$

where $m$ is the mass flow rate of fluid, $A_{\min }$ the minimal flow area that is obtained as: $A_{\min }=A_{c}-A_{p}$. The cross-sectional area $A_{c}$ of the duct is given above in Table 1, while $A_{p}$ is taken as the area of the protrusions. Due to the EB processing, protrusions have irregular wall surfaces. However for analysis purposes, the shape has been approximated to 
be quasi pyramidal with a flat top. Based on this assumption the frontal area of protrusion is a trapezoidal shape and the overall frontal area is evaluated as:

$$
A_{p}=N_{p_{-} \text {front }}\left(\frac{(B+b) H_{p}}{2}\right)
$$

where, $N_{p}$ is the number of protrusions in the cross sectional area of the flow, $B$ the bottom base-width of the protrusion (the bottom base of the trapeze), $b$ is the base-width at the top of protrusion (or the top base of the trapeze) and $H_{p}$ height of protrusion, see figure 6 .

\section{Take Figure 6:}

The Reynolds number and the friction factor for noncircular geometries are based on the hydraulic diameter given as:

$$
D_{h}=\frac{4 A_{\min }}{P_{\text {wett }}}
$$

where $P_{\text {wett }}$, is the wetted perimeter corresponding to the minimal cross flow area and is evaluated as:

$$
P_{\text {wett }}=P_{c h}+N_{p}\left(2 l_{p}+b-B\right)
$$

where $P_{c h}=2\left(W_{c h}+H_{c h}\right)$ is the perimeter of the duct and $l_{p}$ is the length of the protrusion side (or rib of trapeze), see figure 6. Based on the Reynolds number results, the flow is laminar and the hydrodynamic entry length described in [29] is given by as:

$$
L_{h_{-} l a \min a r} \approx 0.05 \operatorname{Re} D_{h}
$$

A parameter of interest in the analysis of fluid flow over EB enhanced structures is the pressure drop $\Delta \mathrm{P}$, since it is directly related to the pumping power and hence the overall 
efficiency. Hydro-dynamically, the fluid flow over irregular enhanced structures is a complex problem, due to hydrodynamic and thermal boundary layers that develop in the surface of each protrusion creating no-slip conditions and flow separation. Therefore it is difficult to analytically predict fluid flow and heat transfer related parameters. Nevertheless for the smooth sample the problem is simpler. The methodology that was followed is presented below.

According to Equation 6, the flow is hydrodynamically developing and the entry length values ranged from $9.6 \mathrm{~cm}$ to $64 \mathrm{~cm}$ depending on Reynolds number. When considering a developing flow in the smooth sample the pressure drop is related to the apparent friction factor, see Shah [30], who proposed the following equation to predict $\left(f_{a p p} \operatorname{Re}\right)$ in the hydrodynamic entry region of circular and noncircular ducts:

$$
f_{a p p} \operatorname{Re}=3.44\left(x^{+}\right)^{-0.5}+\frac{\left(f_{F D} \operatorname{Re}\right)+K(\infty) /\left(4 x^{+}\right)-3.44\left(x^{+}\right)^{-0.5}}{1+C\left(x^{+}\right)^{-2}}
$$

where $f_{a p p}$ is the apparent Fanning friction factor (based on the pressure drop from $L=0$ to $L)$ and is given as:

$$
f_{\text {app }}=\frac{\Delta P}{0.5 \rho V^{2}} \frac{D_{h}}{4 L}=\frac{\Delta P}{0.5 \rho V^{2}} \frac{1}{4 x^{+} \operatorname{Re}_{D_{h}}}
$$

where $x^{+}$is dimensional axial distance, determined as:

$$
x^{+}=\frac{L}{D_{h} \operatorname{Re}_{D_{h}}}
$$

$f_{F D}$ is the fully developed Fanning friction factor, $K(\infty)$ is the incremental pressure drop number that represents the change in momentum between developing and fully developed 
flow, while $C$ is a constant coefficient. The above, $f_{F D}, K(\infty)$ and $C$ depend on the duct geometry, see [27]. Equation 7 can be stated in terms of the pressure drop by replacing $\left(f_{\text {aap }}\right)$ with equation 8 and multiplying both sides by $4 x^{+}$to obtain:

$$
\frac{\Delta P}{0.5 \rho V^{2}}=13.76\left(x^{+}\right)^{0.5}+\frac{4 x^{+}\left(f_{F D} \mathrm{Re}\right)+K(\infty)-13.76\left(x^{+}\right)^{0.5}}{1+C\left(x^{+}\right)^{-2}} .
$$

For the smooth rectangular duct used in current experimental work, the duct aspect ratio $\alpha^{*}=H / W$ is 0.087 . For fully developed flow in rectangular duct, the product $\left(f_{F D} \operatorname{Re}\right)$ can be approximately determined using the following equation, Shah and London [27]:

$$
\begin{aligned}
& f_{F D} \operatorname{Re}=24\left(1-1.3553 \alpha^{*}+1.9467 \alpha^{* 2}-1.7012 \alpha^{* 3}+\right. \\
& \left.0.9564 \alpha^{* 4}-0.2537 \alpha^{* 5}\right)
\end{aligned}
$$

From Equation 11 we obtain, $f_{F D} \operatorname{Re}=21.49$. The incremental pressure drop number $K(\infty)$ is also function of $\alpha^{*}$ and is found from tables in [27]. For the above given duct aspect ratio $K(\infty) \approx 0.76$. The coefficient $C$ also depends on $\alpha^{*}$ and is presented in tables again [27] where it can be evaluated to be $C=5 \times 10^{-5}$. The above values of $\left(f_{F D} \operatorname{Re}\right),(K(\infty))$, and $(C)$ are substituted into equations 7 and 10 to evaluate $\left(f_{a p p} \operatorname{Re}\right)$ and $\Delta P / 0.5 \rho V^{2}$ respectively. The Fanning friction factor for the smooth and the treated samples S1, S2 and S3 is evaluated from experimental data as:

$$
f=\frac{\Delta P D_{h}}{2 L \rho V_{\max }^{2}}
$$

The required pumping power to overcome the pressure loss is determined as:

$$
W_{\text {pump }}=\frac{\dot{m} \Delta P}{\rho}
$$




\section{Heat Transfer}

The heat balance equation for the electrically heated surface can be expressed as:

$$
Q_{\text {elect }}=I V=Q_{\text {conv }}+Q_{\text {loss }}
$$

where $Q$ indicates the heat transfer rate while subscripts elect, conv, and loss represent electric, convection and loss respectively. The heat loss from the system is composed of two components, radiation from the heated surface to the surroundings and second conduction through the insulation and convection to atmosphere. In this case the test section was well insulated and the heat losses have been determined as the difference between the electrical heat input at the cartridge heaters and $Q_{\text {conv }}$. This term is calculated in terms of the enthalpy rise of water which is simply given as:

$$
Q_{\text {conv }}=\dot{m} c_{p}\left(T_{e}-T_{i}\right)
$$

Observation shows that, for the extreme conditions (i.e., when the temperature of the test sample is high) losses reach a maximum of $10 \%$ for all samples. In this study the average convection heat transfer coefficient $h_{a v}$ is calculated based on $Q_{c o n v}$ :

$$
h_{a v}=\frac{\dot{m} c_{p}\left(T_{e}-T_{i}\right)}{A_{s} \Delta T_{L M T D}}
$$

The specific heat capacity of water $c_{p}$ is evaluated at the bulk mean fluid temperature between inlet and outlet. A similar approach in the calculation of the heat transfer coefficient was followed by other researchers [31-32]. $\Delta T_{L M T D}$ is the logarithmic mean temperature difference, and can be determined using the following equation: 


$$
\Delta T_{L M T D}=\frac{\Delta T_{2}-\Delta T_{1}}{\ln \left(\Delta T_{2} / \Delta T_{1}\right)}
$$

$\Delta T_{1}$ and $\Delta T_{2}$ are the temperature differences between the surface $T_{\text {surf }}$ and fluid at inlet and outlet respectively both used to determine the $\Delta T_{L M T D}$.

Since the enhancement is placed in a channel where the side walls are heated the heat transfer area $A_{h t}$ includes bottom (foot print of treated area of the channel) and the two side walls see figure 4 , and is evaluated as:

$$
A_{h t}=\left(W_{c h}+2 H_{c h}\right) L_{c h}
$$

where, $W_{c h}$ is the width, $H_{c h}$ is the height and $L_{c h}$ in the length of the channel.

The temperature at the wetted surface $T_{\text {sur }}$ is obtained at the inlet, centre and outlet based on the measurements of wall temperature at those respective locations as:

$$
T_{\text {surf }}=T_{w}-q\left[\left(\frac{l_{\text {brazing }}}{k_{\text {brazing }}}\right)+\left(\frac{l_{\text {plate }}}{k_{C u}}\right)\right]
$$

where $T_{w}$ is the temperature measured in the heater block, the top thermocouple is located $2.3 \mathrm{~mm}$ below the top surface of the heater block and reminder are equally spaced $4 \mathrm{~mm}$ apart. Hence $T_{w}$ is obtained by fitting an equation through the data measured from thermocouples in the heater block and extrapolating to the top of the heater block. In order to quantify the longitudinal temperature variation along the top surface of the heater block two additional thermocouples are located $3.5 \mathrm{~mm}$ from the upstream and downstream of faces. All heater block temperatures are measured with $0.75 \mathrm{~mm}$ diameter type-T sheathed 
thermocouples, which are secured into $1.0 \mathrm{~mm}$ diameter x $14 \mathrm{~mm}$ deep holes with thermally conductive compound. In equation $9, l_{\text {brazing }}$ is the thickness of the brazing and $l_{\text {plate }}$ is the thickness of the cold plate. Brazing material thickness is $0.08 \mathrm{~mm}$ and thermal conductivity is $371 \mathrm{~W} / \mathrm{m} \mathrm{K}$, while the test sample thickness is $3 \mathrm{~mm}$ copper C101, and conductivity is 391 $\mathrm{W} / \mathrm{m} \mathrm{K}$. The heat flux $q$ is obtained from the enthalpy rise as:

$$
q=\frac{Q_{\text {conv }}}{A_{h t}}
$$

The average Nusselt number is calculated based on the hydraulic diameter of channel and is given as:

$$
N u_{D_{h}}=\frac{h_{a v} D_{h}}{k}
$$

where $k$ is the thermal conductivity of the fluid. The Nusselt number was compared with Stephan (1959) correlation, [28] for developing length in parallel plate channels developed in the range $0.1 \leq \operatorname{Pr} \leq 1000$ and given as:

$$
N u_{a v}=7.55+\frac{0.024 x_{*}^{-1.14}}{1+0.0358 \operatorname{Pr}^{0.17} x_{*}^{-0.64}}
$$

where $x_{*}$ is dimensionless longitudinal coordinate in the thermal entrance region and for parallel plate channel is given as:

$$
x_{*}=\frac{L / D_{h}}{\operatorname{Re}_{D_{h}} \operatorname{Pr}}
$$


Thermal resistance has been evaluated based on the heat transfer coefficient and the footprint of the enhanced surface as:

$$
R_{t h}=\frac{1}{h_{a v} A_{h t}}
$$

\section{UNCERTAINTY ANALYSIS}

The assessment of uncertainty was based on the methodology described in Moffat [33], and the work published by Coleman and Steele [34]. The convection heat transfer coefficient is determined with an uncertainty of $\pm 5 \%$. The average uncertainty in the recorded pressure drop for the smooth sample is approximately $\pm 11.5 \%$, while for the EB treated samples it is $6 \%$. The repeatability tests show that $96 \%$ of the data are reproduced.

\section{EXPERIMENTAL RESULTS}

The pressure drop and heat transfer rates in the smooth (untreated) surface were examined first to help validate the facility and methodology, and to provide the base data for comparison with the enhanced surfaces. The smooth and three EB enhanced samples were tested using the same procedure.

\section{Friction factor}

The friction factor variation with increase of Reynolds number for all four samples is plotted in figure 7. The data indicate a significant scatter of the friction factor for low Reynolds number - less than 600. As the Reynolds number increases the scatter is much less and the friction factor follows a weak decreasing trend with increase of Reynolds number. The theoretical smooth sample friction factor $f_{a p p}$ for developing flow has been obtained using 
the methodology of Shah and London described above Equation 8, while for developed flow in a rectangular cross section equation 11 is used. This is compared to the experimental results obtained using Equation 12 with our pressure and velocity measurements. As seen in Figure 7 the experimental results for the smooth sample are in good agreement with predicted data. Note that all data plotted include error bars. At $\mathrm{Re} \leq 600$ friction is affected by viscous forces the experimental results are predicted by Equation 11, while for $\operatorname{Re} \geq 600$ as flow increases and flow overcome the viscous effects results are predicted from Equation 8.

\section{Take in figure 7}

Friction factor expressions based on the experimental data for the three enhanced samples are developed in the form of Blasius type correlations utilizing a power line fit function and are summarized in Table 2. The correlations predict the data for $600 \leq \mathrm{Re} \leq 1900$. The mean percentage absolute error (MAE) given in Table 2 for each correlation is defined as:

$$
M A E=\frac{1}{M} \sum \frac{\left|f_{\exp }-f_{\text {pred }}\right|}{f_{\text {exp }}} * 100 \%
$$

where $M$ is total number of data points.

Take in table 2.

Figure 8 presents the thermal resistance versus pumping power as suggested by [7] and [12] in order to compare enhancement techniques. The thermal resistance decreases with increasing pumping power for all samples due to increase of fluid velocity and hence the convection heat transfer coefficient. As seen in the figure for a given pumping power the thermal resistance of all three samples is much lower than the resistance of the smooth plate verifying the effectiveness of the enhanced surfaces. The thermal resistance of Samples S1 
and S3 is similar for a range of pumping powers while the resistance of sample S2 is higher, particularly at higher pumping power.

\section{Take in figure 8}

\section{Heat Transfer}

The variation of heat flux with surface temperature at a constant $0.045 \mathrm{~kg} / \mathrm{s}$ mass flow rate $(\operatorname{Re} \approx 1850)$ for all four samples is presented in figure 9. The heat flux increases linearly with the surface temperature for constant flow rate due to increase of temperature difference between fluid and the surface. The effectiveness of the enhanced surfaces is obvious. For example a heat flux of $300 \mathrm{~kW} / \mathrm{m} 2$ can be transferred with a wall surface temperature of 33 ${ }^{\circ} \mathrm{C}$ for sample S3 that increases to $36{ }^{\circ} \mathrm{C}$ and $47{ }^{\circ} \mathrm{C}$ for samples $\mathrm{S} 1$ and S2 respectively. While for the same heat flux the corresponding surface temperature for the smooth test section is $59{ }^{\circ} \mathrm{C}$. These observations suggest that all treatments and in particular sample S3 and S1 can be suitable for removing high heat fluxes and maintain the electronic equipment at relative low operating temperature. EB enhanced surfaces can achieve high heat flux i.e. heat fluxes increase by $20 \mathrm{~kW}$ for each degree increase in the surface temperature for sample S3. Therefore enhanced surfaces can be used effectively in cooling systems for automotive, high-performance and cost-performance category. Technology can be applied on heat exchange equipment to improve natural and forced convection. EB enhanced surfaces can improve thermal efficiency, reduce the size heat exchange devise, improve reliability, safety and economic efficiency.

\section{Take figure 9}

Figure 10 presents the variation of the average Nusselt number with increasing Reynolds number. As observed in the figure, the Nusselt number increases with Reynolds number for 
all the test samples including the smooth test sample. The Nusselt number for sample S1 is 3.5 times larger than that of the smooth test section, followed by sample S3 that depicts an increase in Nuselt number by approximately 2.5 times and sample S2 by approximately 2 times. The Nusselt number for the smooth sample was compared with that predicted from Stephan (1959) for developing flow [28, 35]. The experimental data are in good agreement with the Stephan correlation.

Take in figure 10

The heat transfer data from the experimental work were correlated by a Dittus and Boelter type relationship of the form $N u_{a v}=C \operatorname{Re}^{m} \operatorname{Pr}^{n}$ utilising the power line function, see Table 3 . The mean percentage absolute error of averaged Nusselt number is determined employing identical methodology used at equation 25 and results are presented in Table 3.

Take in table 3

The comparison of the heat transfer and friction ratios versus Reynolds number is presented in figure 11 in terms of the efficiency index. This is an important parameter in assessing the overall performance of an enhanced surface, see [36]. This index can be defined as follows:

$$
\eta=\frac{h / h_{s}}{f / f_{s}}
$$

where $h$ is the heat transfer coefficient and $f$ friction factor. Values with subscript $s$ refer to the smooth or plain test section. High values indicate good surfaces, i.e. heat transfer rates are achieved without a significant penalty in pressure drop and hence pumping power. On the contrary small values of the efficiency index means that a high increase in pressure drop is required to achieve the enhancement level that may be needed. The efficiency index decreases rapidly with the Reynolds number for all the enhanced samples. Sample S1 and S3 
have relatively better efficiency indexes compared to sample S2. This is due to the low heat transfer coefficient experienced in sample S2 in comparison with other two.

Take in figure 11

\section{CONCLUSIONS}

The primary aim of this study was to provide an experimental evaluation of heat transfer and pressure drop for the laminar regime of deionised water flow in three EB enhanced surfaces, and compare these to a smooth surface tested under the same conditions. The results obtained have been presented and discussed in terms of friction factor and Nusselt number, and the following conclusions can be drawn:

Electron beam enhancement technology is a good way to improve heat removal capacity of liquid cold plates. The three electron beam enhanced surfaces tested have significantly higher Nusselt numbers compared to the smooth test section. However, the pressure drop is also higher and the best possible solution can only be reached if we consider the heat transfer performance as well as the pressure drop together.

The friction factor in the smooth surface was in agreement with that predicted using established relationships such as that of Shah and London. The pressure drop obtained with the EB enhanced structures was significantly higher than that of smooth surface sample. The friction factor as expected increases noticeably with increase of the protrusion density, sample S3 which has the higher protrusion density and lowest hydraulic diameter gave the highest pressure drop. Sample S1 gave the highest Nusselt number followed by sample S3 and S2. The high heat transfer coefficients obtained confirm that the samples can meet the demand of high power heat removal. During the experimental work heat fluxes of $370 \mathrm{~W} / \mathrm{m}^{2}$ 
were removed from sample S3 with a surface temperature of $38^{\circ} \mathrm{C}$, every $10^{\circ} \mathrm{C}$ increase on the surface temperature increased heat fluxes by $200 \mathrm{~kW} / \mathrm{m}^{2}$.

The relationship between thermal resistance and pumping power was presented for practical evaluation. Enhanced samples S1 and S3 gave the lower thermal resistance at a given pumping power. This is due to high protrusion density and flow velocity. Therefore if both the heat removal rates as well as pumping power are equally important those two should be preferred over S2.

A comparison of the thermal and hydraulic performance was performed also by assessing the relationship between the efficiency index and the Reynolds number. Samples S1 and S3 achieved the highest efficiency index for a given Reynolds number. This is the result of their balanced hydraulic and thermal performance. Sample S2 performed better in pressure drop terms but gave a low efficiency due to the low thermal performance. Therefore, if both the heat removal rate and the pumping power are equally important, S1 and S3 should be preferred over surface S2. Optimisation of these structures is possible if we consider carefully the protrusion geometry and density and evaluate both the heat transfer and pressure drop performance. 


\begin{tabular}{|c|c|}
\hline$A_{h t}$ & Heat transfer area, $\mathrm{m}^{2}$ \\
\hline$A_{c}$ & Cross-sectional area, $\mathrm{m}^{2}$ \\
\hline$A_{p}$ & Area of protrusions, $\mathrm{m}^{2}$ \\
\hline$B$ & Fin base width \\
\hline$b$ & Fin top width \\
\hline$C$ & Constant coefficient \\
\hline$c_{p}$ & Specific heat capacity, J/kg K \\
\hline$D_{h}$ & Hydraulic diameter, $\mathrm{m}$ \\
\hline$f$ & Friction factor \\
\hline$H$ & Height, m \\
\hline$h$ & Heat transfer coefficient, $\mathrm{W} / \mathrm{m}^{2} \mathrm{~K}$ \\
\hline$k$ & Thermal conductivity, W/m K \\
\hline$K(\infty)$ & Incremental pressure drop number \\
\hline$L$ & Length, $\mathrm{m}$ \\
\hline$l$ & Thickness, $\mathrm{m}$ \\
\hline$l_{p}$ & Protrusion side rib length, m \\
\hline$M$ & Total number of data points \\
\hline$\dot{m}$ & Mass flow rate, $\mathrm{kg} / \mathrm{s}$ \\
\hline$N$ & Frontal number of protrusions \\
\hline$I$ & Current, Amp \\
\hline$P$ & Wetted perimeter, $\mathrm{m}$ \\
\hline$\Delta P$ & Pressure drop, $\mathrm{Pa}$ \\
\hline$Q$ & Heat Transfer rate, $\mathrm{W}$ \\
\hline$q$ & Heat flux, W/m² \\
\hline
\end{tabular}




$\begin{array}{ll}q, & \text { Heat transfer rate per unit length, W/m } \\ R & \text { Thermal Resistance, K/W } \\ T & \text { Temperature, }{ }^{\circ} \mathrm{C} \\ \Delta T & \text { Temperature difference, }{ }^{\circ} \mathrm{C} \\ U & \text { Voltage, } \mathrm{V} \\ V & \text { Velocity, } \mathrm{m} / \mathrm{s} \\ W & \text { Width, } \mathrm{m} \\ W_{\text {pump }} & \text { Pumping power, } \mathrm{W}\end{array}$

Greek letters

$\begin{array}{ll}\alpha^{*} & \text { Ratio width to height } \\ \mu & \text { Dynamic viscosity, Pa s } \\ \rho & \text { Fluid density, } \mathrm{kg} / \mathrm{m}^{3}\end{array}$

Dimensionless groups

$\begin{array}{ll}\mathrm{Nu} & \text { Nusselt number, } \mathrm{Nu}=\mathrm{hD} / \mathrm{h} / \mathrm{k} \\ \operatorname{Pr} & \text { Pandtl number, } \mathrm{Pr}=\mu \mathrm{cp} / \mathrm{k} \\ \operatorname{Re} & \text { Reynolds number, } \mathrm{Re}=\rho \mathrm{VD}_{\mathrm{h}} / \mu \\ x & \text { Thermal entry length, } \mathrm{m} \\ x+ & \text { Dimensionless axial distance } \\ x_{*} & \text { Dimensionless axial distance for thermally developing flow } \\ \eta & \text { Efficiency index, } \mathrm{\eta}=(\mathrm{h} / \mathrm{hs}) /(\mathrm{f} / \mathrm{fs})\end{array}$

Subscripts

$\begin{array}{ll}\text { app } & \text { Apparent } \\ \text { av } & \text { Average }\end{array}$




\begin{tabular}{|c|c|}
\hline$c$ & Cross section \\
\hline cond & Conduction \\
\hline Conv & Convection \\
\hline$C h$ & Channel \\
\hline $\mathrm{Cu}$ & Copper \\
\hline$e$ & Exit \\
\hline Elect & Electrical \\
\hline $\operatorname{Exp}$ & Experimental \\
\hline$F D$ & Fully developed \\
\hline$i$ & Inlet \\
\hline LMTD & Log-mean temperature difference \\
\hline $\max$ & Maximum \\
\hline $\min$ & Minimum \\
\hline$p$ & Protrusion \\
\hline pred & Predicted \\
\hline th & Thermal \\
\hline$h$ & Hydraulic \\
\hline$h t$ & Heat transfer \\
\hline$s$ & Smooth \\
\hline surf & Surface \\
\hline$W$ & Wall \\
\hline
\end{tabular}

\section{ACKNOWLEDGMENTS}

The authors would like to acknowledge Dr Anita Buxton and Dr Bruce Dance of TWI for their contribution to this project and also EPSRC and TSB for funding the EngD programme and sponsoring the ASTIA collaborative research project that helped to develop the Electron Beam enhanced surfaces respectively. 


\section{REFERENCES}

[1] McGlen, R.J., Jachuck, R. \& Lin, S., "Integrated thermal management techniques for high power electronic devices", Applied Thermal Engineering, vol. 24, no. 8, pp. 1143-1156, 2004.

[2] Bergles, A., E. and Webb, R. L., "A Guide to the Literature on Convective Heat Transfer Augmentation", in Advances in Enhanced Heat Transfer - 1985, Eds., S. M. Shenkman, J.E. O'Brien, I. S. Habib, and J.A. Kohler, ASME Symposium, Vol-HTD. 43, pp 81-90, 1985.

[3] Reay, D. A., "Heat transfer enhancement - A review of techniques and their possible impact on energy efficiency in the U.K", Heat Recovery Systems \& CHP, vol. 11, 1991.

[4] Webb, R. and Kim, N., "Principles of Heat Transfer", 3 edition, Taylor \& Francis NY, pp.1-20, 2005.

[5] Bejan, A., Kraus, A. D., Heat Transfer Handbook, $2^{\text {nd }}$ edition, John Wiley \& Sons, pp. 424-430, 2003.

[6] Sara, O.N., Pekdemir, T., Yapici, S. and Yilmaz, M., "Heat-transfer enhancement in a channel flow with perforated rectangular blocks", International Journal of Heat and Fluid Flow, vol. 22, no. 5, pp. 509-518, 2001.

[7] Wang, Q., Chen, Q., Wang, L., Zeng, M., Huang, Y., and Xiao., Z., "Experimental study of heat transfer enhancement in narrow rectangular channel with longitudinal vortex generators", Nuclear Engineering and Design, vol. 237, no. 7, pp. 686-693, 2007. 
[8] Dong, J., Chen, J., Chen, Zh., and Zhou, Y., "Air-side thermal hydraulic performance of offset strip fin aluminium heat exchangers", Applied Thermal Engineering, vol. 27, pp. 306-313, 2007.

[9] Webb, R L., "Single-phase heat transfer, friction, and fouling characteristics of threedimensional cone roughness in tube flow", International Journal of Heat and Mass Transfer, vol. 52, pp. 2624-2631, 2009.

[10] Yang, K., Chu, W., Chen, I. \& Wang, C., "A comparative study of the airside performance of heat sinks having pin fin configurations", International Journal of Heat and Mass Transfer, vol. 50, no. 23, pp. 4661-4667, 2007.

[11] Rosa, P., Karayiannis, T.G. and Collins, M.W., "Single-phase heat transfer in micro channels: The importance of scaling effects", Applied Thermal Engineering, vol. 29, no. 17-18, pp. 3447-3468, 2009.

[12] Peles, Y., Koşar, A., Mishra, C., Kuo, C. and Schneider, B., "Forced convective heat transfer across a pin fin micro heat sink", International Journal of Heat and Mass Transfer, vol. 48, no. 17, pp. 3615-3627, 2005.

[13] Zimparov, V., "Energy conservation through heat transfer enhancement techniques", International Journal of Energy Research., vol. 26, pp. 675-696, 2002.

[14] Liu, M. Liu, D. Xu, Sheng. Chen, Y., "Experimental study on liquid flow and heat transfer in micro square pin fin heat sink", International Journal of Heat and Mass Transfer, vol.54, pp. 5602-5611, 2011.

[15] Siu-Ho, A. M., Qu, W. and Pfefferkorn, F., "Hydrodynamic and thermal characteristics of single-phase and two-phase micro-pin-fin heat sinks", Proceedings 
of IMECE 2007, International Mechanical Engineering Congress and Exposition. ASME, Nov 2007.

[16] Copetti, J. B., "Experiments with micro-fin tube in single phase", International Journal of Refrigeration, vol. 27, pp. 876-883, 2002.

[17] Liu, M. Liu, D. Xu, Sheng. Chen, Y., "Experimental study on liquid flow and heat transfer in micro square pin fin heat sink", International Journal of Heat and Mass Transfer, vol.54, pp. 5602-5611, 2011.

[18] Ma, X., Ding, G., Zhang, Y. \& Wang, K., "Airside heat transfer and friction characteristics for enhanced fin-and-tube heat exchanger with hydrophilic coating under wet conditions", International Journal of Refrigeration, vol. 30, no. 7, pp. 11531167, 2007.

[19] Yu, E. and Joshi, Y., "Heat transfer enhancement from enclosed discrete components using pin-fin heat sinks", International Journal of Heat and Mass Transfer, vol. 45, no. 25, pp. 4957-4966, 2002.

[20] Kosar, A., Mishra, C., and Peles, Y., "Laminar flow across a bank of low aspect ratio micro pin fins", ASME Journal of Fluids Engineering, 127, pp. 419-430, 2005.

[21] Siddique, M. and Alhazmy, M., "Experimental study of turbulent single-phase flow and heat transfer inside a micro-finned tube", International Journal of Refrigeration, vol. 31, pp. 234-241, 2008.

[22] Siu-Ho, A. M., Qu, W. and Pfefferkorn, F., (2006) "Pressure drop and heat transfer in a single-phase micro-pin-fin heat sink", Proceedings of IMECE 2006, International Mechanical Engineering Congress and Exposition. ASME 2006. 
[23] Naphon, P., Klangchart, S., and Wangwises, S., "Numerical investigation on the heat transfer and flow in the mini-fin heat sink for CPU", International Communications in Heat and Mass Transfer, vol. 36, pp. 834-840, 2009.

[24] Wong, M., Owen, I., Sutcliffe, C.J. and Puri, A., "Convective heat transfer and pressure losses across novel heat sinks fabricated by Selective Laser Melting", International Journal of Heat and Mass Transfer, vol. 52, no. 1-2, pp. 281-288, 2009.

[25] Dance, B. G. I., and Buxton, A. L, "An introduction to Surfi-Sculpt technology - New opportunities, new challenges", Proceedings of 7th International Conference on Beam Technology, Halle, Germany, 2007.

[26] Buxton, A. L., Ferhati, A., McGlen, R.J., Dance, B. G. I., Mullen, D. and Karayiannis, T. G., "Electron Beam Surface Engineering for High Performance Heat Exchangers", First International Electron Beam Welding Conference, Chicago, IL, USA, 2009.

[27] Shah, R. K. and London, A. L., Laminar Flow Forced Convection in Ducts, Supplement 1 to Advances in Heat Transfer, Academic Press, New York, 1978.

[28] Bejan, A. Kraus, A. D., Heat Transfer Handbook. John Wiley \& Sons, Inc, Canada, 2003.

[29] Cengel, Y.A., Heat and Mass Transfer.3 ed. McGraw-Hill, pp. 469, 2006.

[30] Shah, R. K., "A correlation for laminar hydrodynamic entry length solutions for circular and noncircular ducts". J. Fluids Eng., 100, Jun, pp. 177-179, 1978.

[31] Qu, W. Siu-Ho, A., "Experimental study of saturated flow boiling heat transfer in an array of staggered micro-pin-fins", International Journal of Heat and Mass Transfer, vol.52, pp. 1853-1863, 2009. 
[32] Halimic, E. Mullen, D. Agnew, B., "Effect of micro-channel size, heat flux and mass flux on flow boiling heat transfer", 11th UK Heat Transfer Conference, 2009.

[33] Moffat, R. J., "Describing the Uncertainties in Experimental Results", Experimental Thermal and Fluid Science, vol.1, pp. 3-17, 1988.

[34] Coleman, H. W., and Steele, W. G., Experimental, validation, and uncertainty analysis for engineers, $3^{\text {rd }}$ edition, John Wiley \& Sons, Inc, 2009.

[35] Stephan K, Warmeubergang und drauckabfall bei nicht ausgebildeter Laminarstromung in Rohren und inebenen Spalten, Chem.-Ing.-Tech., Vol 31, pp. 773-778, 1959.

[36] Han, D. H., and Lee, K. J., "Single-phase heat transfer and flow characteristics of micro-fin tubes", Applied Thermal Engineering, vol. 25, pp. 1657-1669, 2005. 


\section{List of Figures}

Figure 1: Electron beam cooper enhanced test samples. $\quad 31$

Figure 2: Schematic of the test flow loop. 31

Figure 3: Test module assembly. 32

Figure 4: Interior view of test sample. 32

Figure 5: Schematic view of test module. 33

Figure 6: Pressure drop vs. Reynolds number. 33

Figure 7: The apparent friction factor vs. Reynolds number. 33

Figure 8: Thermal resistance vs. pumping power. 34

Figure 9: Heat flux vs. surface temperature for $(\mathrm{Re} \approx 1850)$ and inlet fluid temperature $19{ }^{\circ} \mathrm{C}$. 35

Figure 10: Avarage Nusselt number vs. Reynolds number. 30

Figure 11.Efficiency index vs. Reynolds number 31

List of tables

Table 1: Protrusion and channel dimensions. 26

Table 2: Friction factor correlations. 29

Table 3: Average Nusselt number correlations.31 


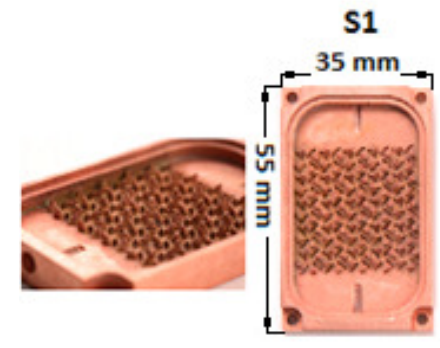

S2

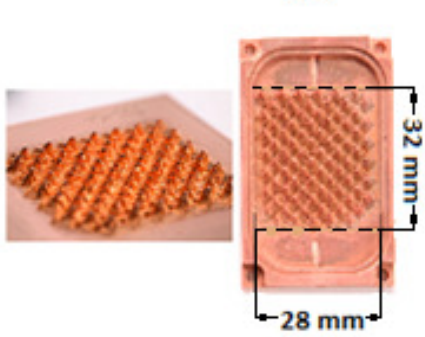

S3

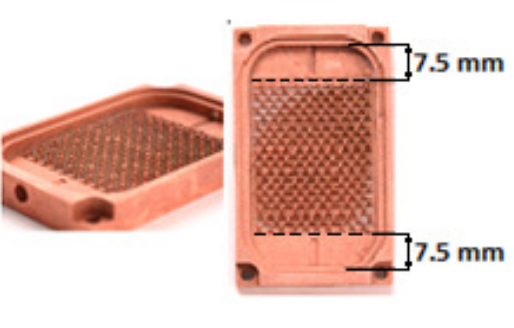

Figure 1: Electron beam cooper enhanced test samples. 


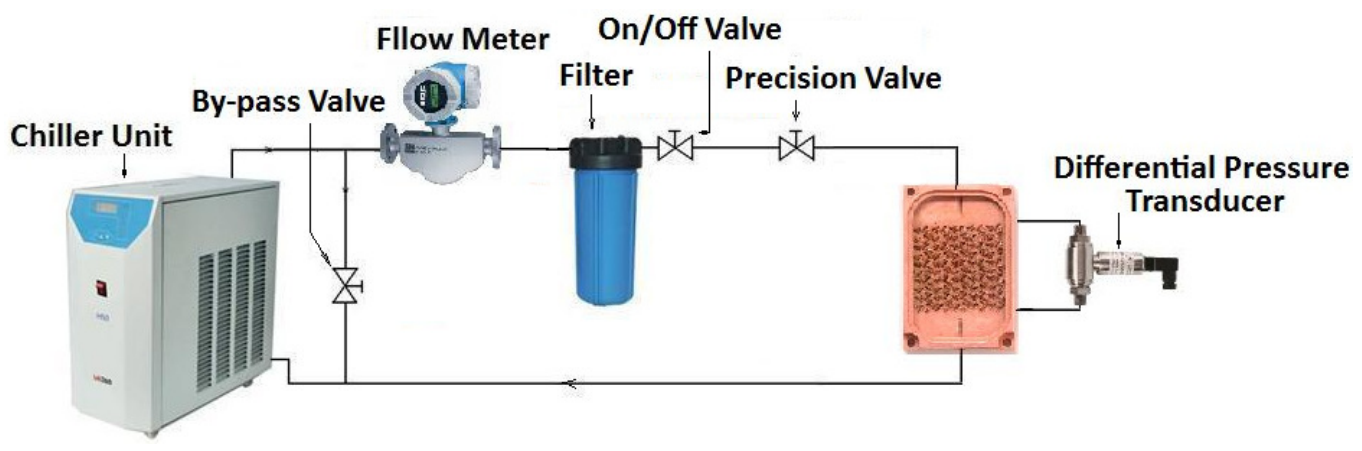

Figure 2: Schematic of the test flow loop. 


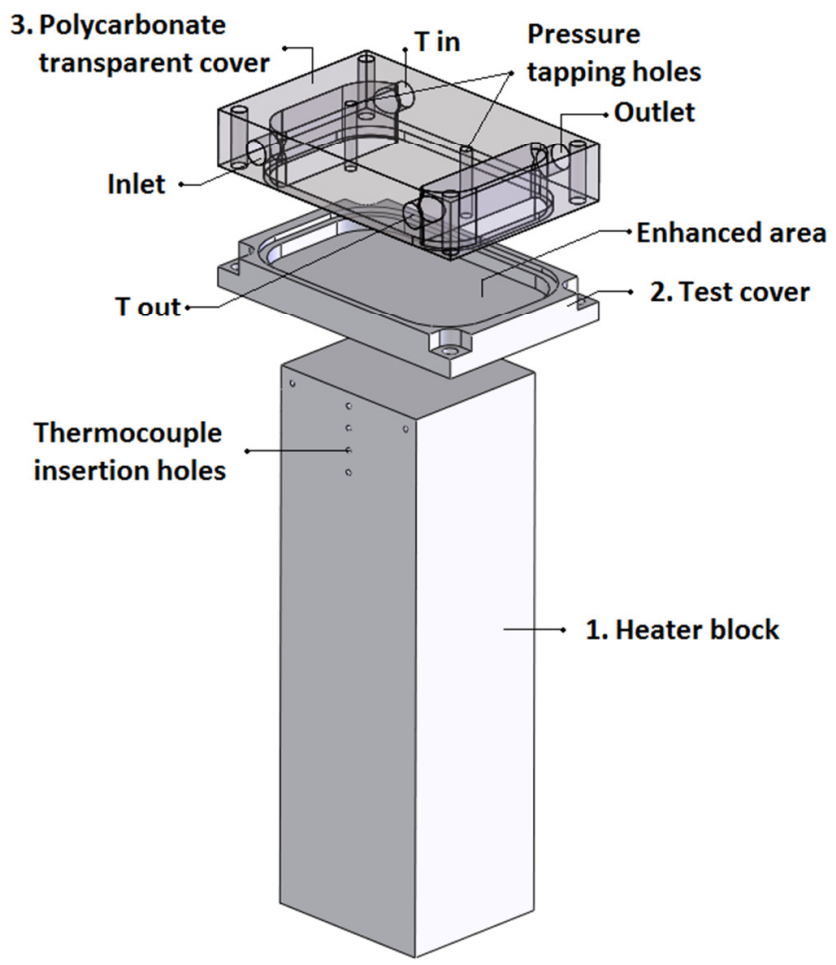

Figure 3: Schematic view of the test module. 


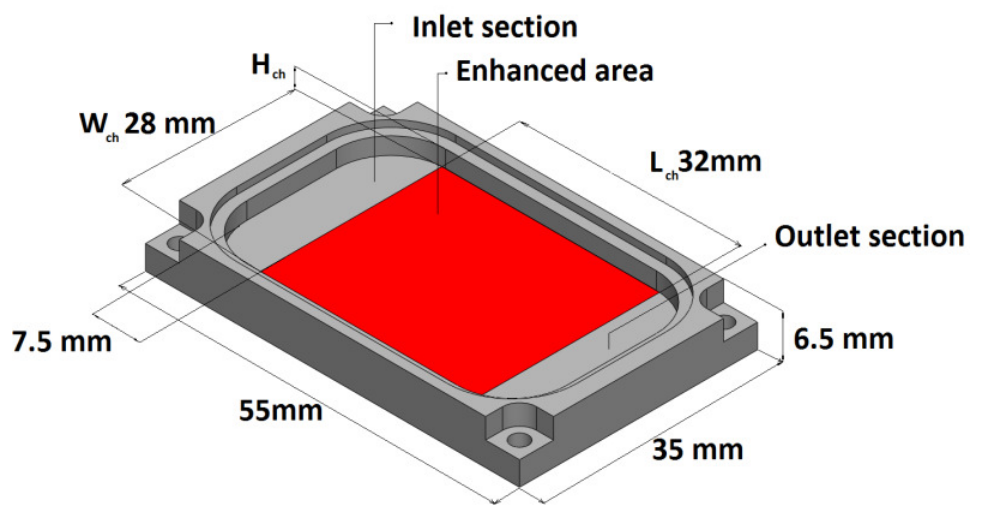

Figure 4: Interior view of test sample. 


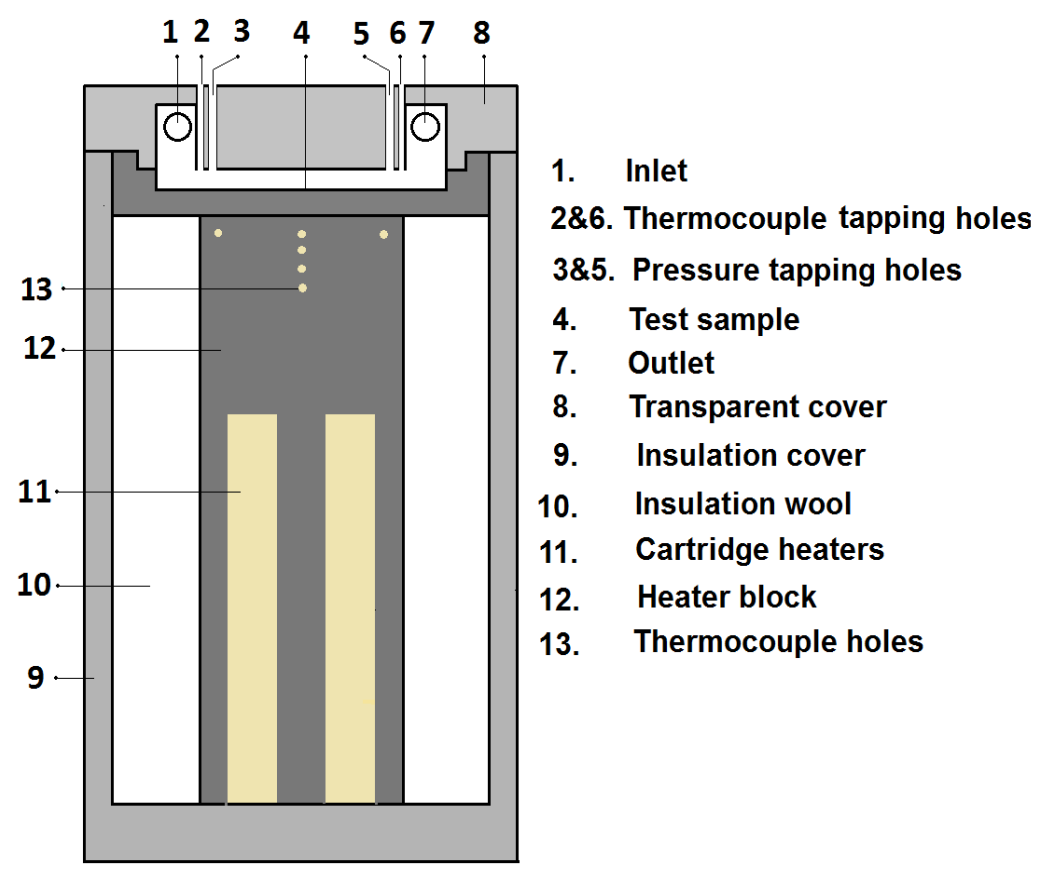

Figure 5: Schematic view of test module. 


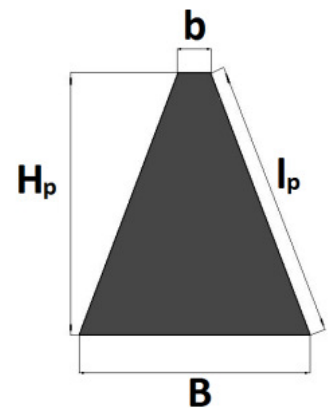

Figure 6: Frontal view perpendicular to the flow of the fin. 


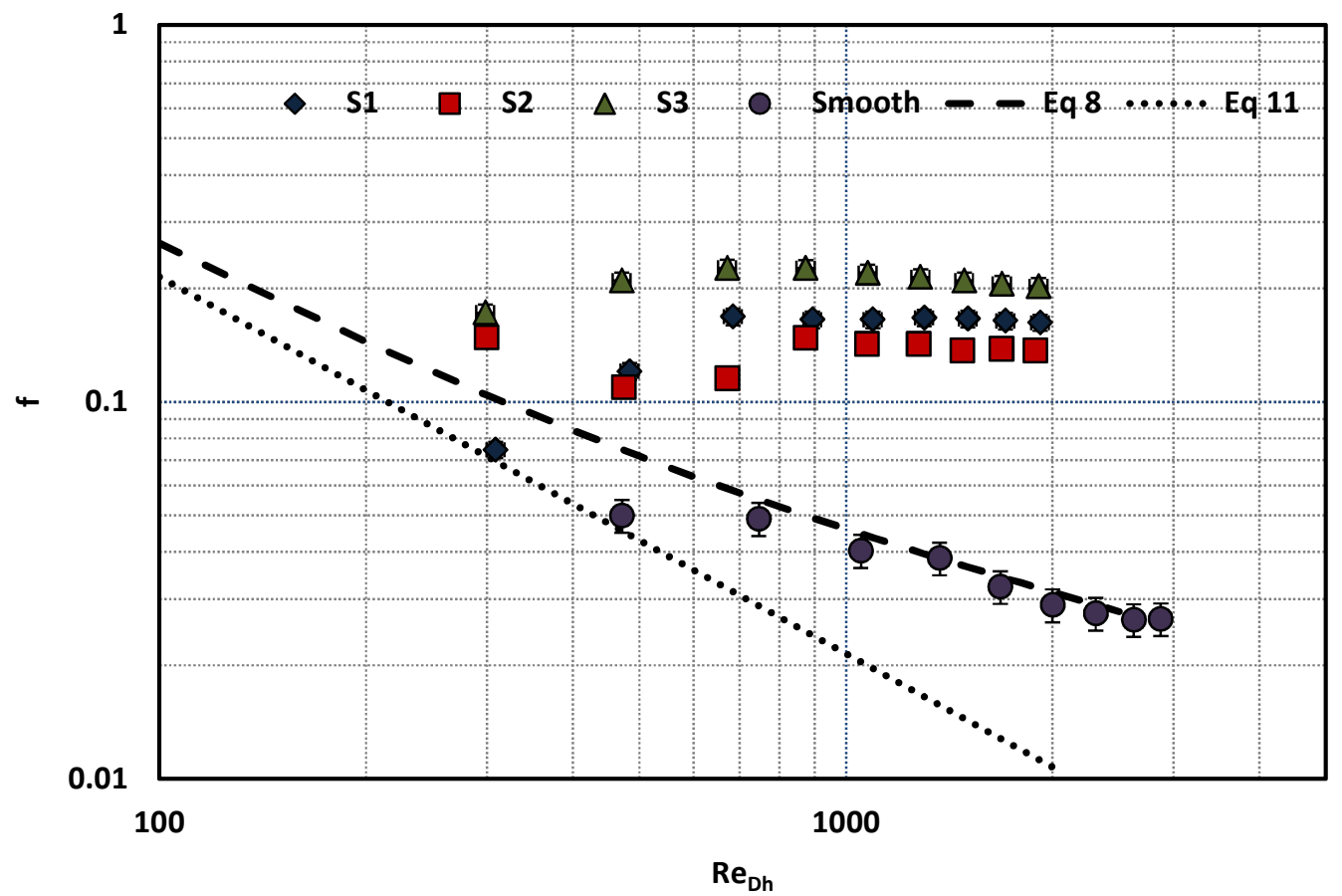

Figure 7: Friction factor versus Reynolds number 


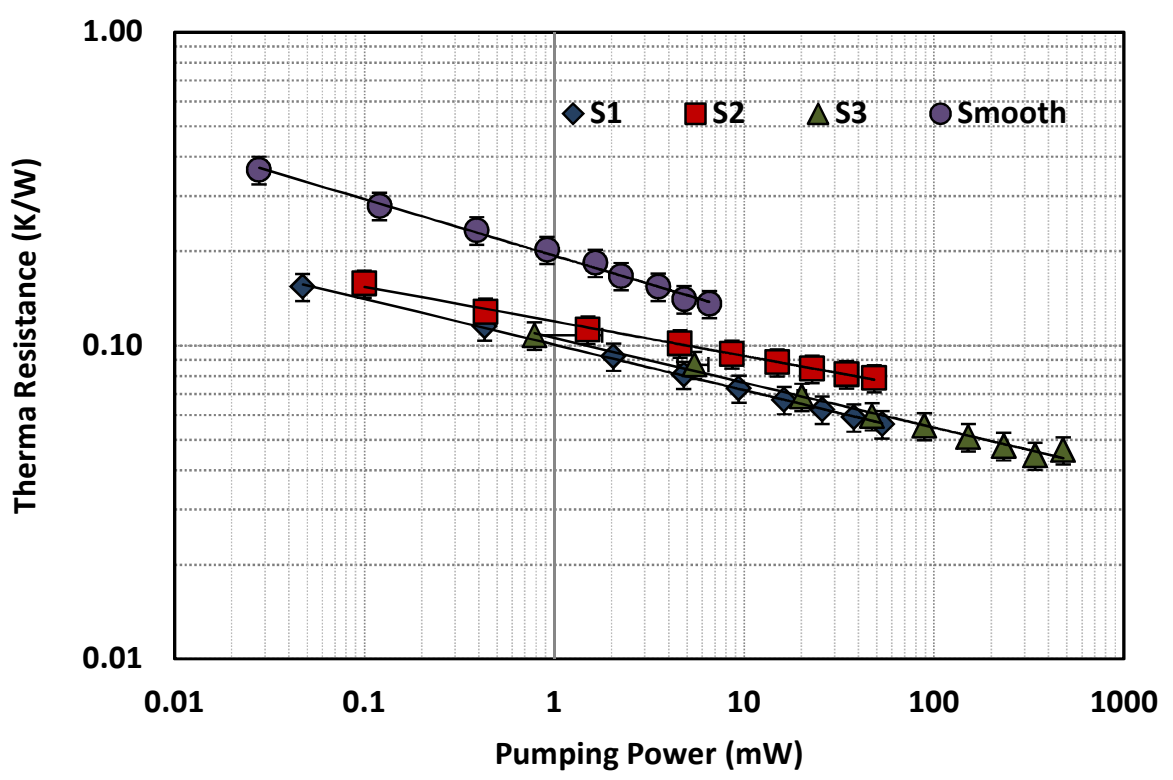

Figure 8: Thermal resistance versus pumping power 


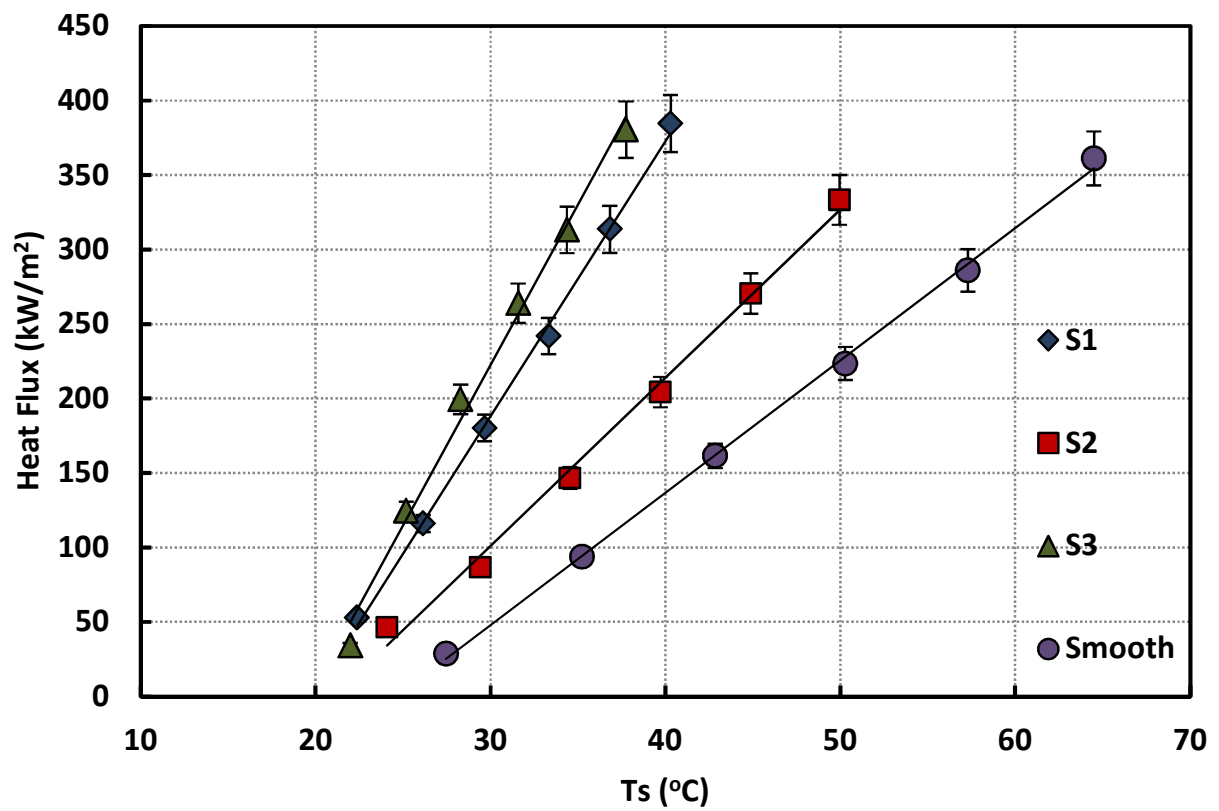

Figure 9: Heat flux versus surface temperature for constant mass flow of $0.045 \mathrm{~kg} / \mathrm{s},(, \operatorname{Re} \approx$ 1850 ) and inlet fluid temperature $\approx 19{ }^{\circ} \mathrm{C}$. 


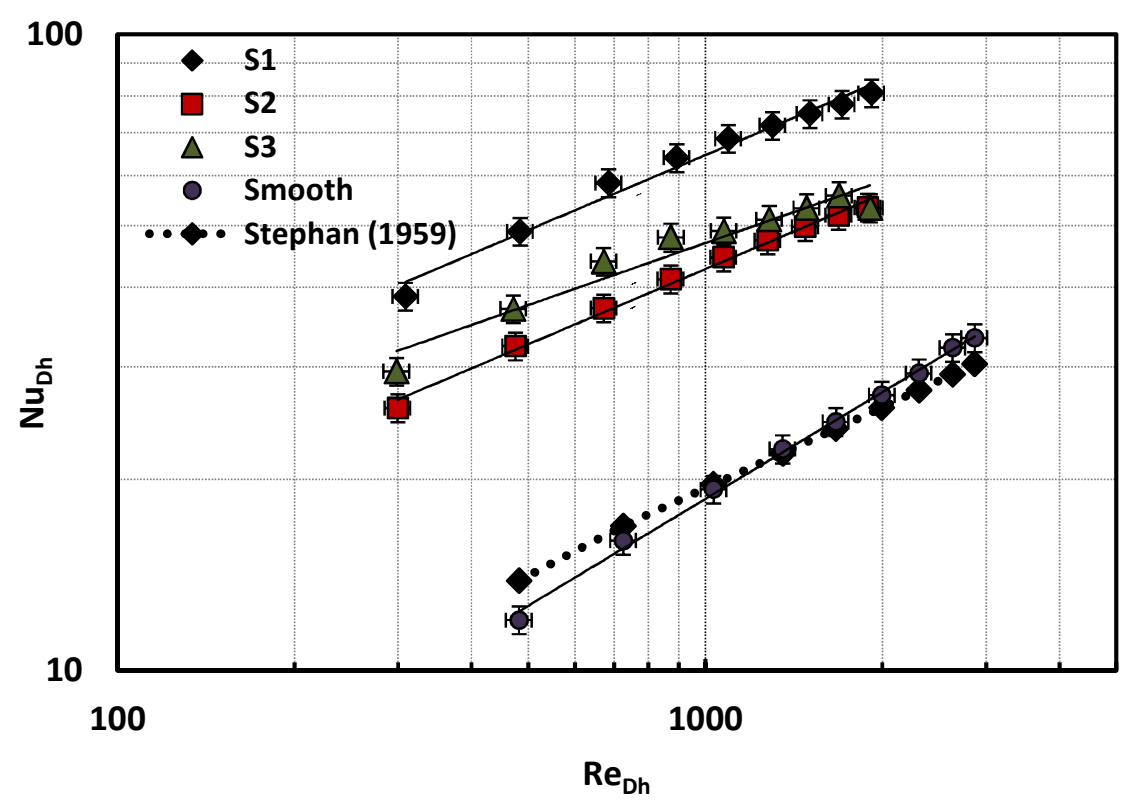

Figure 10: Nusselt number versus Reynolds number 
Table 1: Protrusion and channel dimensions.

\begin{tabular}{lllllll}
\hline $\begin{array}{l}\text { Test } \\
\text { Sample }\end{array}$ & $\begin{array}{l}\mathrm{S}_{\mathrm{T}} \\
(\mathrm{mm})\end{array}$ & $\begin{array}{l}\mathrm{S}_{\mathrm{L}} \\
(\mathrm{mm})\end{array}$ & $\begin{array}{l}\mathrm{H}_{\mathrm{P}} \\
(\mathrm{mm})\end{array}$ & $\begin{array}{l}\mathrm{H}_{\mathrm{ch}} \\
(\mathrm{mm})\end{array}$ & $\begin{array}{l}\mathrm{A}_{\mathrm{c}} \\
(\mathrm{mm} 2)\end{array}$ & $\begin{array}{l}\mathrm{D}_{\mathrm{h}} \\
\mathrm{mm}\end{array}$ \\
\hline $\mathrm{S} 1$ & 5.6 & 2.8 & 2.5 & 2.80 & 82 & 3.00 \\
$\mathrm{~S} 2$ & 4.3 & 2.1 & 2.8 & 2.87 & 84 & 2.80 \\
$\mathrm{~S} 3$ & 2.6 & 1.5 & 1.6 & 1.68 & 49 & 1.59 \\
Smooth & - & - & - & 2.45 & 67 & 4.51 \\
\hline
\end{tabular}


Table 2: Friction factor correlations.

\begin{tabular}{cccc}
\hline $\begin{array}{c}\text { Test } \\
\text { Sample }\end{array}$ & Correlation & $\begin{array}{c}\text { Reynolds } \\
\text { number }\end{array}$ & MAE \% \\
\hline \hline $\mathrm{S} 1$ & $\mathrm{f}=0.17-0.9 * 10^{-3} \mathrm{Re}^{0.33}$ & $600-1900$ & 2.18 \\
\hline $\mathrm{S} 2$ & $\mathrm{f}=0.18-3.4 * 10^{-3} \mathrm{Re}^{0.33}$ & $600-1800$ & 2.80 \\
\hline $\mathrm{S} 3$ & $\mathrm{f}=0.31-8.9 * 10^{-3} \mathrm{Re}^{0.33}$ & $600-1800$ & 1.20 \\
\hline Smooth & $\mathrm{f}=0.08-3.9 * 10^{-3} \mathrm{Re}^{0.33}$ & $600-1800$ & 4.1 \\
\hline
\end{tabular}


Table 3: The heat transfer data correlations, Reynolds number applicability and mean absolute error.

\begin{tabular}{llll}
$\begin{array}{l}\text { Test } \\
\text { Sample }\end{array}$ & Correlation & $\begin{array}{l}\text { Reynolds } \\
\text { number }\end{array}$ & $\begin{array}{l}\text { MAE } \\
\%\end{array}$ \\
\hline \hline S1 & $\mathrm{Nu}=3.52 \operatorname{Re}^{0.33} \operatorname{Pr}^{1 / 3}$ & $290-1900$ & 7.7 \\
S2 & $\mathrm{Nu}=2.38 \mathrm{Re}^{0.33} \operatorname{Pr}^{1 / 3}$ & $230-1800$ & 5.2 \\
S3 & $\mathrm{Nu}=2.63 \operatorname{Re}^{0.33} \operatorname{Pr}^{1 / 3}$ & $230-1900$ & 10 \\
\hline
\end{tabular}




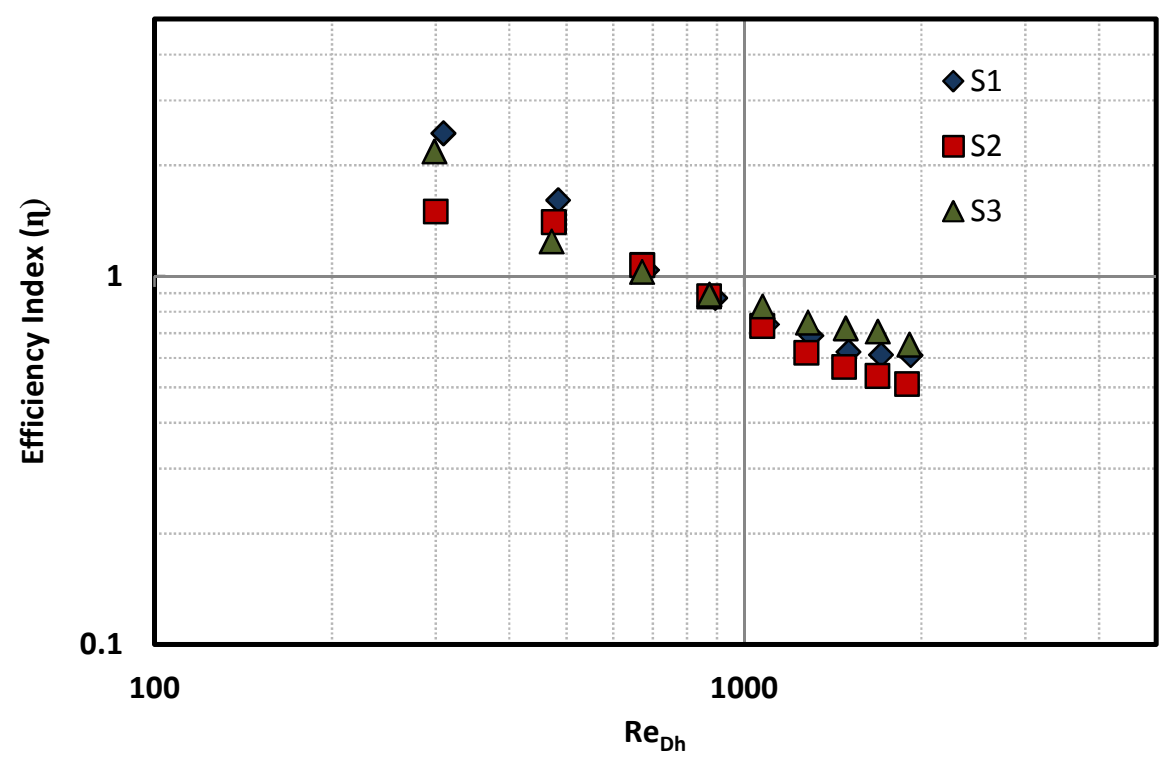

Figure 11: Efficiency index vs. Reynolds number 

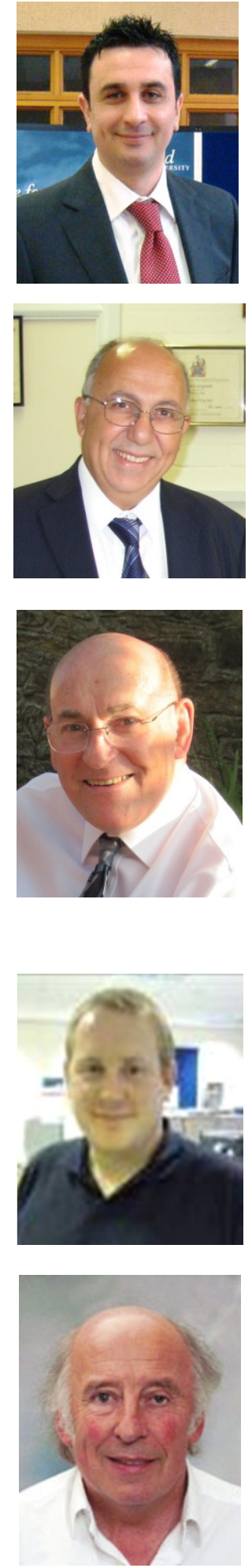

Arben Ferhati is an EngD student at Brunel University under the supervision of Prof. Tassos Karayiannis. He received in 1998 a Diploma of Engineering in Energy from Tirana Polytechnic University in Albania and an MSc degree in Energy Systems and Thermal Processes from Cranfield University, United Kingdom. Current research interests include thermal management technologies for electronics sector and the development of efficient heat transfer enhancement technologies for liquid cooling applications.

Tassos G. Karayiannis is Professor of Thermal Engineering in the School of Engineering and Design of Brunel University, where he is co-director of the Centre for Energy and Built Environment Research (CEBER). He obtained a BSc in Mechanical Engineering from City University (UK) in 1981 and a PhD from the University of Western Ontario (Canada) in 1986. He has carried out research in single-phase heat transfer, enhanced heat transfer and thermal systems. He has been involved with research in two-phase flow and heat transfer for about 20 years. He is a fellow of the Institution of Mechanical Engineers and the Institute of Energy

John S. Lewis started his engineering career in the gas turbine industry and studied mechanical engineering at Lanchester College of Technology, Coventry and aircraft propulsion at the College of Aeronautics, Cranfield before working at the Engineering Sciences Data Unit on design data items for heat transfer. From 1972 to 2006 he held academic positions at Middlesex University. He is now a visiting research fellow at the School of Engineering and Design, Brunel University. He received his $\mathrm{PhD}$ from the City University, London, in 1992, for research on combined convection and has also worked on heat and mass transfer in spray systems and cooling towers. His current research is on single-phase and boiling heat transfer in microchannels. He is a member of the Institution of Mechanical Engineers and the Royal Aeronautical Society.

Dr Ryan McGlen is Senior Advanced Technologies Engineer at Thermacore Europe ltd. where he leads research and development of future heat pipe technologies. Current research interests include novel heat pipe materials and working fluids combinations and additive layer manufacture of aluminium heat pipes with complex 3D Sintered Style wicks (SSHP).

David Reay is a Professor of Thermal Engineering and founder of David Reay and Associates, Consulting Engineers. He is a Visiting Professor in Engineering at a number of universities in the United Kingdom. He teaches modules in energy, process intensification and technology futures. Professor Reay was awarded the Brennan Medal, with his co-authors, in 2008 by The Institution of Chemical Engineers. His research interests include carbon capture, heat transfer intensification, compact heat exchangers, heat pipe and heat pump technology. $\mathrm{He}$ is Editor-in-Chief of Applied Thermal Engineering, and was the first Honorary Life member of the Heat Pump Association. He is Co-ordinator of the Heat Exchanger Action Group and Co-ordinator of the Process Intensification Network. 